\title{
LAS IMPLICANCIAS DEL MARKETING INTERNACIONAL EN UN ENTORNO GLOBALIZADO
}

\author{
THE IMPLICATIONS OF INTERNATIONAL \\ MARKETING IN A GLOBALIZED ENVIRONMENT
}

Jorge Luis Escalante Flores ${ }^{1 ;}$ a

(iD) ORCID iD 0000-0002-4942-5283

1 Universidad Ricardo Palma. Facultad de Ciencias Económicas y Empresariales. Escuela Profesional de Administración de Negocios Globales.

a Doctor en Administración.

El marketing internacional tiene gran importancia debido a que el mundo se ha globalizado. Cada vez con mayor frecuencia hacemos honor a la sentencia del filósofo griego Sócrates, quien afirmó: "Soy ciudadano, no de Atenas o de Grecia, sino del mundo". El marketing internacional nos rodea todos los días, tiene un efecto importante en nuestras vidas y ofrece nuevos desafíos y oportunidades.

El marketing internacional es necesario, ya que desde el punto de vista local el aislamiento económico se ha vuelto imposible. No integrarse y participar en el mercado global asegura la disminución de la capacidad económica de un país y de los estándares de vida de los ciudadanos. Sin embargo, el marketing internacional exitoso mantiene la promesa de una calidad de vida cada vez mejor, una mejor sociedad, transacciones comerciales más eficientes e incluso un mundo más pacífico.

Czinkota y Ronkainen (2008) definen el marketing internacional como el proceso de planeación y realización de transacciones a través de las fronteras nacionales con el fin de crear intercambios que satisfagan los objetivos de los individuos y las organizaciones. El marketing internacional asume diferentes formas que van desde el comercio de importaciones y exportaciones al licenciamiento, empresas conjuntas o joint ventures, subsidiarias en propiedad completa, operaciones de soluciones integrales y contratos de administración. 
Con esta definición, el marketing internacional mantiene gran parte de los principios básicos del marketing de "satisfacción" e "intercambio". El marketing internacional es una herramienta que se emplea para obtener una mejora en la posición en la que se está en el presente. El hecho de que una transacción tenga lugar a través de las fronteras nacionales señala la diferencia entre marketing local e internacional. La empresa internacional está sujeta a una serie de factores macro ambientales, diferentes restricciones y conflictos muy frecuentes, resultados de diferentes leyes, culturas y sociedades. Por ejemplo, cuando se observan las economías de mercados emergentes de China y Rusia, se pueden ver los diferentes nuevos retos que enfrenta el marketing internacional. ¿De qué manera el concepto de marketing encaja en esta sociedad?, ¿Cómo puede contribuir el marketing al desarrollo económico y al progreso de una sociedad?, ¿Cómo deben organizarse los sistemas de distribución? y ¿Cómo se logra que la política de precios funcione? De manera similar en las áreas internacionales de responsabilidad social y ética, la empresa internacional se enfrenta actualmente a un entorno multicultural con distintas expectativas y, con frecuencia, a sistemas legales incongruentes en lo referente al monitoreo de la contaminación ambiental.

De acuerdo a Cateora (1995), la tarea del marketing internacional es más complicada que la del nacional porque el internacional debe tratar, por lo menos, con dos niveles de incertidumbre incontrolable en lugar de uno. La incertidumbre es creada por los elementos incontrolables de todos los entornos empresariales, pero cada país extraño en el que una compañía opera agrega su conjunto propio y único de elementos no controlables. Los elementos más significativos en el entorno incontrolable internacional incluyen fuerzas políticas y legales, fuerzas económicas, fuerzas competitivas, nivel de tecnología, estructura de distribución, geografía e infraestructura y fuerzas culturales. Constituyen los elementos principales de la incertidumbre con los que una empresa internacional debe lidiar al diseñar un programa de marketing

Para ajustar y adaptar un programa de marketing a mercados extranjeros, los responsables de marketing deben ser capaces de interpretar efectivamente la influencia y la repercusión de cada uno de los elementos incontrolables del entorno sobre el plan de marketing para cada mercado extranjero en el que espera realizar negocios. Sin embargo, independientemente de los recursos utilizados para obtener acceso a un mercado extranjero, una compañía puede desde el punto de vista del marketing no realizar inversiones de mercado, es decir su compromiso de marketing puede limitarse a vender un producto con poca o ninguna idea de desarrollar un control del mercado.

Cuando un responsable de marketing opera en otras culturas, los intentos de marketing pueden fallar debido a respuestas inconscientes, basadas en marcos de referencia aceptables dentro de la cultura propia pero inaceptable en ambientes diferentes. Por ejemplo, un occidental debe aprender que el blanco es un símbolo de luto en algunas partes del Lejano Oriente, lo que es bastante distinto del blanco que se utiliza en la cultura occidental para los vestidos de novia. Para evitar tales errores, la empresa extranjera debe ser consciente del principio de relativismo de marketing, es decir que las estrategias y los juicios de marketing se basan en la experiencia y cada agente interpreta la experiencia en términos de su propia cultura. La tarea del ajuste cultural es, tal vez, la más ardua e importante que afrontan las empresas internacionales; deben ajustar sus esfuerzos de marketing a culturas con las que no están armonizadas.

Según Cateora (1995), el marketing internacional es la realización de las actividades de negocios que dirigen el flujo de bienes y servicios de una compañía hacia sus consumidores o usuarios en más de una nación para obtener un beneficio. La única diferencia en las definiciones del marketing nacional e internacional es que las actividades de marketing ocurren en más de un país. Esta aparentemente minúscula diferencia explica la complejidad y diversidad halladas en las operaciones internacionales de marketing. Sin embargo, para el autor, el concepto de extensión del mercado nacional está representado por la compañía nacional que busca la extensión de las ventas de sus productos nacionales hacia mercados extranjeros. Ve sus operaciones internacionales como secundarias y como una extensión de sus operaciones nacionales; el motivo principal es disponer del exceso de la producción nacional.

Después de que una compañía reconoce la importancia de las diferencias en los mercados extranjeros y la importancia del negocio en el exterior para su organización, su orientación hacia el negocio internacional puede cambiar a una estrategia de mercado internacional. Una compañía guiada por este concepto tiene una fuerte sensación de que los mercados por países son vastamente distintos (y que pueden serlo, dependiendo del producto) y que el éxito del mercado requiere un programa casi independiente para cada país. Las empresas con esta orientación venden en cada país con estrategias de marketing separadas para cada uno.

Finalmente, una compañía que emplea una estrategia de marketing global debe procurar las economías de 
escala al desarrollar un producto estandarizado, de calidad fiable, que puede venderse a un precio razonable en un mercado global; es decir, el mismo mercado del país establecido para todo el mundo. Es importante para el concepto de marketing global, buscar, en gran medida, las mismas formas de satisfacer de satisfacer sus necesidades y deseos. Así, constituyen importantes segmentos de mercado con demandas similares para el mismo producto en todo el mundo. Con este enfoque, una empresa intenta estandarizar al máximo el esfuerzo de la compañía tanto como sea prácticamente posible sobre una base mundial.

\section{REFERENCIAS}

Cateora, P. 1995. Marketing Internacional. Madrid: Edición Irwin.

Czinkota, M. y Ronkainen, I. 2008. Marketing Internacional. México D.F.: Editorial Cengage Learning.

Correo electrónico para correspondencia:

jorge.escalante@urp.edu.pe 